\title{
Geological Services tow ards a Sustainable Use and Management of the Subsurface: A Geoethical Imperative
}

\author{
SERGE F. VAN GESSEL \\ Geological Survey of the Netherlands (TNO), Utrecht, The Netherlands \\ serge.vangessel@tno.nl \\ KLAUS HINSBY \\ Geological Survey of Denmark and Greenland (GEUS), Copenhagen, Denmark \\ khi@geus.dk \\ GERRY STANLEY \\ Geological Survey of Ireland (GSI), Dublin, Ireland \\ gerry.stanley@gsi.ie \\ JøRGEN TULSTRUP \\ Geological Survey of Denmark and Greenland (GEUS), Copenhagen, Denmark \\ jtu@geus.dk \\ YVONNE SCHAVEMAKER \\ Geological Survey of the Netherlands (TNO), Utrecht, The Netherlands \\ yvonne.schavemaker@tno.nl \\ KRIS PIESSENS \\ Royal Belgian Institute of Natural Sciences - Geological Survey of Belgium, Brussels, Belgium \\ kpiessens@naturalsciences.be \\ PAUL J.F. BOGAARD \\ Geological Survey of the Netherlands (TNO), Utrecht, The Netherland s \\ paul.bogaard@tno.n1
}

\begin{abstract}
A Geological Service for Europe provides users with tailored and transnational consistent information on subsurface resources, capacities and processes within their surrounding environment. Such information underpins the responsible management of subsurface space and its resources, which is often administered by different authorities. National and regional geological surveys have come together to develop much-needed innovations and improvements that will integrate information and knowledge across different geological and geographical settings in Europe. This cooperative framework aims to meet societal challenges and protect valuable resources for future generations while ensuring that geoethical principles are honored.
\end{abstract}




\section{BACKGROUND}

$\mathrm{T}$ he Earth, along with energy from the Sun, is the source of all that is necessary to sustain life and provide the raw materials that support humankind, society and our way of life. When we consider what sustains life, we think of food, plants, animals and water. When we consider what supports our lifestyle, we consider our shelter (homes and clothing); sources of energy - including hydrocarbons, nuclear, and renewables such as solar, wind and geothermal; raw materials for everyday living; modern technologies including the manufacture of goods, devices and tools; transport (land, sea and air); and energy generation, transmission and storage. Altogether the subsurface is a vital element for these commodities, be it as provider of crucial resources (w ater, energy, minerals), a reservoir for temporary buffering of resources, a sink for permanent storage of waste, a footing for surface and subsurface constructions and infrastructure including tunnels and buildings, or the foundation for preserving clean environments and unique nature reserves.

The UN forecasts that in 2050 the global population will reach $9.77 \mathrm{bn}$ from $7.6 \mathrm{bn}$ today (UN, 2017). With increasing numbers of people comes increasing pressure for the secure supply of raw materials, water and energy to su pport the population. In 1983 the United Nations established the Brundtland Commission to examine issues critical to the environment and development. The Commission focused its attention on the areas of population, food security, the loss of species and genetic resources, energy, industry, and human settlements - realizing that all of these are connected and cannot be treated in isolation one from another. The final report was published in 1987 and proposed the concept of "sustainable development" which was defined as:

"Sustainable development is development that meets the needs of the present without compromising the ability of future generations to meet their own needs."

It has been widely adopted around the world and led the United Nations to develop the 2030
Agenda for Sustainable Development and its 17 Sustainable Development Goals (SDG) (United Nations, 2015a and 2015b). In particular SDGs No. 6 (Clean water and sanitation); 7 (Affordable and clean energy); 9 (Industry, innovation and infrastructure); 12 (Responsible consumption and production), 13 (Climate action), 14 (Life below water) and 15 (Life on land) apply to the issues under discussion in this paper water, energy and raw materials. Similarly, the European Union focused its efforts on a total of 7 Societal Challenges (SCs) through the H2020 research and innovation program. Aspects of these challenges are either directly (e.g. water, energy, raw minerals) or indirectly (e.g. food, health, climate, environment and biodiversity) related to the use or preservation of subsurface space and resources and the water-food-energy nexus (Bazilian et al., 2011).

The far-reaching impact and influence of SCs and SDGs extend beyond the national scale, and the need for transnational information and cooperation is illustrated by the following examples:

- The markets for some minerals (in particular metals) and energy resources are increasingly globalized. International dependencies with regards to their supply can strongly influence economies and societies at a national scale. Secure supply of resources is an important factor in creating or maintaining such strong economies and also in preserving political stability (Andrews-Speed et al., 2017; EC, 2011). Transnational collaboration on management of resources is crucial in this context, considering the fact that most subsurface resources are determined by location-specific geological conditions and therefore unequally distributed by definition.

- Emission reduction and transition from fossil fuel generation systems to renewable energy generation systems present us with a significant challenge to secure and balance future energy supply strategies. This requires international cooperation and the successful management of different energy generation and storage solutions including the exploration and safe extraction of various types of subsurface energy resources. 
- The mitigation and reduction of human impacts on climate change is a major societal challenge for Europe and many other countries across the globe (EC, 2014) as climate change will affect the entire planet. The predicted changes in climate and rise in sea level will have a profound impact on groundwater and surface water systems (Treidel et al., 2012). The ability to adapt to these changes and the options to accommodate to impacts will vary from region to region. Yet our success in protecting ecosystems, keeping areas habitable and securing the safety of citizens and supplies of clean drinking water (Hinsby et al., 2008), will depend on how we cooperate in developing joint solutions. It has been argued that the human impact on earth has severely affected the environment and crossed planetary boundaries and thresholds e.g. biogeochemical flows of nitrogen and phosphorus in the Anthropocene (Steffen et al., 2007 and 2015).

The subsurface is an important part of the systems integration needed for global sustainability in the future (Liu et al., 2015), and our selection of options must be based on (geo)ethical considerations (Martínez-Frías, et al., 2011; Peppoloni and Di Capua, 2017).

\section{A PARADIGM FOR A GEOLOGICAL SERVICE FOR EUROPE}

Geoscientists and Geological Survey Organizations (GSOs) have a key responsibility to support the realization of SDGs and Societal Challenges with reliable and unbiased subsurface information and advice. The continuous improvement, maintenance and public dissemination of this information and advice, as well as the scientific tools and methods needed for such provisions, are together described in this paper as "geological services".

Geological services provide the information for evidence-based decision-making on issues with both short and long-term perspectives. Geoscientific information is critical to the provision of evidence to back whatever course of action is proposed for any specific situation. It is largely collected and constructed for public good by GSOs - either national or regional - throughout
Europe. As geology is such a wide scientific endeavor, each GSO may focus on a particular sub-discipline (ranging from geohazards to water resources and the environment; from hydrocarbons to geothermal; and from construction materials to metal raw materials) depending on national priorities. As a result the state of knowledge in any one sub-discipline varies from one GSO to another. Information collected by one GSO may be different from another and it is often not easy to integrate data and information across jurisdictions. Geology, however, does not recognize the borders between countries - geological formations transcend these boundaries and water and other fluids flow (freely) across the borders above and below ground. The fore-mentioned transnational context of Societal Challenges and continuity of geological features and resources across borders should therefore be reflected by the geological services as well.

The key scientific challenge for GSOs and associated science institutes is thus to overcome the fundamental differences in the way geological services are established and composed at national and regional level. These differences exist for various reasons, e.g.:

- Different scope and level of subsurface exploration and exploitation resulting in contrasting data patterns and qualities.

- Different approaches, formats and standards for mapping, modeling and analyzing subsurface data (e.g. 2D vs. 3D, definition of geological units, scale and accuracy).

- Different jurisdictions may have regulations covering what data can or cannot be shared and used.

In order to serve end-u sers effectively, the geoscientist must transform data and knowledge into solutions that directly relate to the decision or alternatives under evaluation. For example: "Where can $\mathrm{CO}_{2}$ be safely stored and in what quantities?", "Should a certain mineral deposit be considered for development?", or "What measures must be implemented to mitigate and monitor impacts on a groundwater body?"

Geological surveys provide such answers by measuring and modeling subsurface structure and properties in four dimensions, and using 


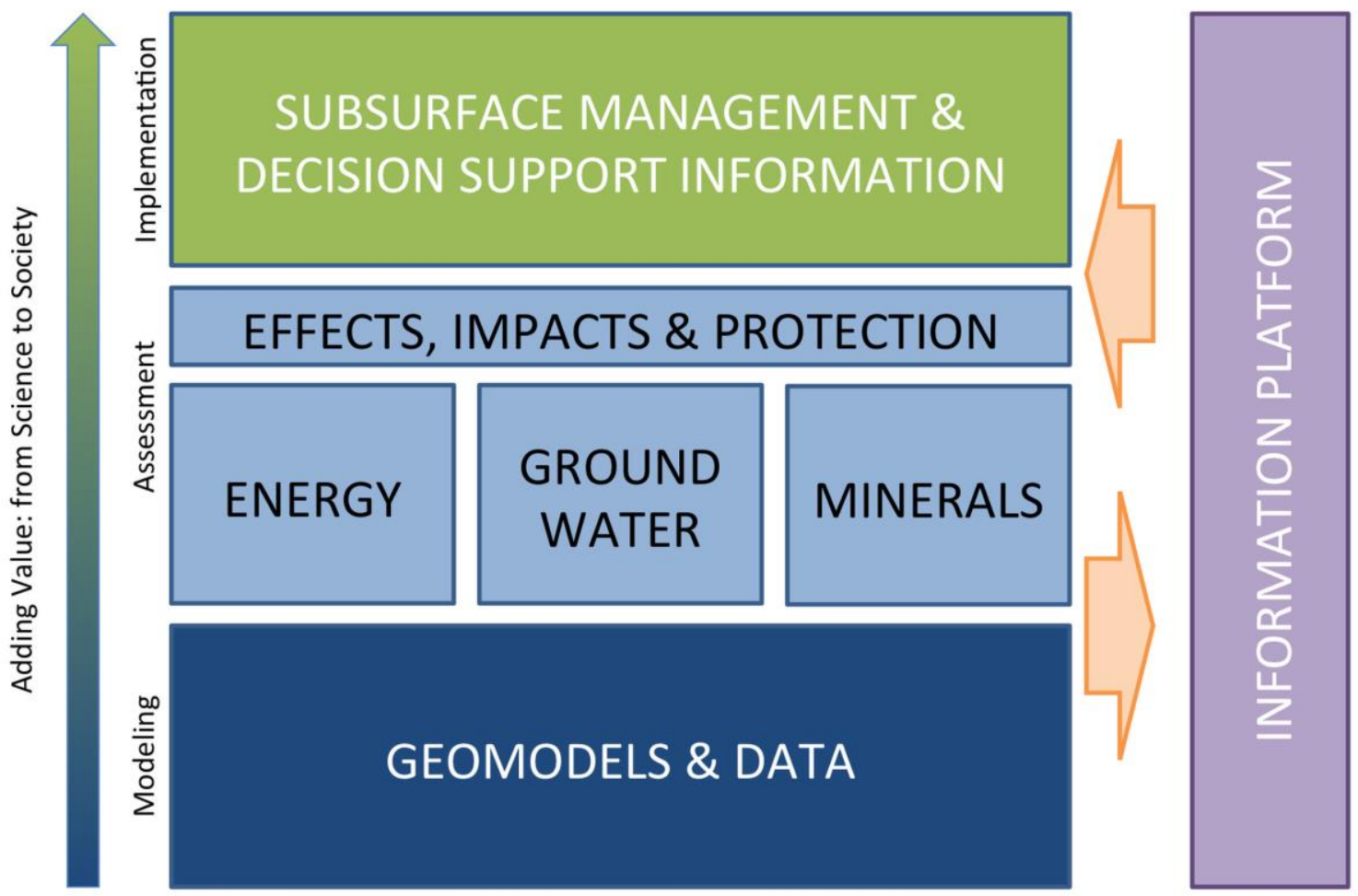

Figure 1: Generic workflow underpinning the presented Geological Service for Europe. In this concept, subsurface management and resource assessments are linked to the consistent $3 D$ geomodels from which they are derived.

resulting data and geo-models to assess the distribution and exploitability of resources and capacities, as well as the possible effects induced by subsurface activities. The integration of these outcomes in the multi-dimensional geo-model space helps the decision-makers to appreciate their spatial-temporal relationships and enables further appraisal of the viability and possible consequences of development scenarios. This approach is reflected by the generically applicable workflow principles in Fig. 1.

The key to establishing an effective and sustainable geological service at European level lies in a proper transnational harmonization of each step in this workflow, while respecting the unique and highly variable geological characteristics and societal aspects within individual regions. In the following sections the key scientific challenges tow ards establishing this in a European context are briefly described for each of the main workflow stages. As will be demonstrated later in this paper, the idea to realize a European Geological Service is not merely driven by pragmatic reasons, although ample benefits are associated with reaching across national and geological borders. At the hearth of this lies the realization that geoethical principles require an accepted and durable European structure for sharing of data, methods, expertise, views and even responsibilities.

\subsection{Geo-models and data}

Subsurface data and measurements are typically converted into 2D, 3D or 4D geo-models representing the spatial layout of geological units and structures, rock and fluid properties, interacting subsurface processes (van der Meulen et al., 2013) at various spatial and temporal scales. By extrapolating data and information into a higher dimensional space (e.g. 1D wells or drill holes into 2D cross-sections or 3D layer models) or converting information from one type into another (e.g. 3D seismic into 3D structure and properties), predictions can be made on 
whether certain geological conditions are likely or possible at particular locations. Moving information into higher dimensions also makes it possible to assess various spatial and temporal relationships between different rock units and the dynamic processes within these units. The consistent correlation and linkage of measurements within geologically modeled units enables their analysis in an appropriate genetic context. The effectiveness of transnational subsurface management strongly relies on a consistent collation and correlation of geo-model information across borders. This brings a major challenge with regards to how the variety of models and measurements from different regions and geological settings can be merged or integrated. In addition to the geological aspects (e.g. stratigraphic definitions), this task also requires solutions in information management (e.g. dealing with different scales, geometries and model standards).

\subsection{Resources and utilization: Energy, Ground water and Minerals}

Subsurface resources and capacities are either identified directly from observations (e.g. in wells or drill holes) or predicted from a combination of indicative properties and favorable geological conditions represented in the geomodels. A harmonized European overview of geological resources and potential subsurface uses will of course rely on the quality and consistency of underpinning data (e.g. obtained from surface or airborne geophysics). The application of comparable and uniform assessment methodologies and criteria is of equal importance, especially when the end results are used in international resources and reserves classification schemes. Making sure that such methodologies are able to deal with the specifics of individual regions (geological setting, available data, exploration level, etc.), and that the various geological uncertainties are properly accommodated in the end results, are key scientific challenges in this respect.

\subsection{Effects, impacts and protection}

The consequences of subsurface development are in most cases restricted to the specific loca- tion where the activities take place, yet their manifestation often has a far-reaching influence on society.

The evaluation and understanding of the subsurface processes and conditions that lead to induced hazards and environmental impacts presents significant scientific challenges. Relevant on-site information may often be sparse and appropriate analogues difficult to find.

Geological surveys can bring much-needed innovation to this field of research by sharing experiences, merging and integrating crucial data sets and jointly developing best practices and innovative methodologies.

Transnational harmonized 2D/3D/4D geomodels will greatly assist in a proper exchange and comparison of analogue systems and thereby enable new insights into causes, effects and trends. The same is true for the efficient development of innovative approaches that rely on harmonized input data.

It is this broad collaboration that will pave the way for improved national and EU guidance on the safe development of the subsurface and an improved and common understanding of the hazards and impacts, both within and between Member States.

\subsection{Subsurface management and decision support information}

The establishment of integrated and coherent management of subsurface resources and uses in Europe is one of the important goals of a $\mathrm{Eu}$ ropean Geological Service.

The steps outlined above will facilitate decision-making that is underpinned by consistent and comparable data, information and knowledge. Subsurface management and decision support involves the development of common principles and strategies on how to transform and incorporate this data and information into common subsurface decision and management protocols.

Again, the 2D/3D/4D geological framework will be crucial for the appropriate evaluation and representation of spatial-temporal interactions and dependencies, and the anticipation of conflicts and synergies arising from development scenarios of different resources by different Member States. 


\section{INFORMATION STAND ARDS AND DISSEMINATION : A FUNDAMENTAL PRE-REQUISITE FOR GEOLOGICAL SERVICES}

A proper European Geological Service can only function and be relevant if it can provide complete, up-to-date and interoperable data and information on an on-going basis. The European Union, as a party to the Aarhus Convention, recognizes the following rights in this context:

1. Provide access to environmental information;

2. Provide the public the right to participate in environmental decision making; and

3. Provide a mechanism to review procedures on decisions made with respect to the environment, which have not respected the two previous rights or environmental law in general.

To that end a common information platform must be developed that shares and exchanges data and results between all countries and disciplines. Not only will the platform be important for the dissemination of information and results to end-users. It will also drive the proper implementation of the measurement-todecision workflows by delivering the critical model architectures, functionalities, standards and metadata structures. Such structures and functionalities define the basis for add-on webservices developed by third parties or within Public-Private-Partnerships between the GSO's and relevant stakeholders e.g. for the European Environment Agency.

The European Union INSPIRE Directive (EC, 2007) establishing an Infrastructure for Spatial Information in the European Community aims to facilitate the harmonization and standardization of spatial data and make the data Findable, Accessible, Interoperable and Reusable according to the "FAIR" principles (Wilkinson et al., 2016). Geoscience data is one of the spatial data themes within the remit of INSPIRE. As such it requires the construction of a common terminology. To this purpose GSOs, among others, have participated in developing code-lists, e.g. for minerals within the Minerals4EU project. However, the development and implementa- tion of code-lists for other aspects is a task that should be achieved by the envisioned Geological Service for Europe.

\section{SOCIETAL CHALLENGES AND GEOLOGICAL SERVICES FOR THE SUSTAINABLE DEVELOPMEN T: A GEOETHICAL IMPERATIVE}

The concept of geological services within the European context is intertwined with the fundamental principles of Geoethics.

The definition of geoethics, as proposed by the International Association for Promoting Geoethics (http:/ / www.geoethics.org, accessed 15 May 2018), is:

"Geoethics consists of research and reflection on the values which underpin appropriate behaviors and practices, wherever human activities interact with the Earth system. Geoethics deals with the ethical, social and cultural implications of geoscience education, research and practice, and with the social role and responsibility of geoscientists in conducting their activities."

The geoscience community needs to promote an ethical approach tow ards science and practice of research. This will be a core principal at the heart of delivering a Geological Service for Europe. The term "geoethics" is used from ' 90 (Peppoloni and Di Capua, 2015), and the growing awareness in the geological community for the need to take ethics into consideration in its work precedes the current definition (Wyss \& Peppoloni, 2015).

The "Cape Town Statement on Geoethics" (Di Capua et al., 2017) describes the fundamental values of geoethics:

- Ensuring sustainability of economic and social activities in order to assure future generations' supply of energy and other natural resources.

- Sharing knowledge at all levels as a valuable activity, which implies communicating science and results, while taking into account intrinsic limitations such as probabilities and uncertainties.

- Verifying the sources of information and data, and applying objective, unbiased 
peer-review processes to technical and scientific publications.

These statements provide clear references to the eminent position of geoethics as an underpinning principle for geoscientists and geoscientific information and knowledge to follow while addressing societal challenges and the SDGs. As such, geological services include geoethics values as they are aimed at safeguarding the exploration and safe development of natural resources and subsurface capacities based on impartial and scientifically validated information and knowledge, always having the interests of society as a core value.

\section{CONCLUDING REMARKS AND OUTLOOK}

International economic developments, resource dependencies, climate change impacts, energy transition, growing societal aw areness, and the need for new technologies and advanced understanding, are all important drivers for a uniform and interoperable European Geological Service. This service supports the collaborative management and protection of subsurface resources and capacities and can only be relevant if it can continuously provide complete, up-todate, and harmonized subsurface information. To that purpose the national and regional geological surveys of Europe are taking a major step by establishing the precursor of a European Geological Service through close collaboration within the dedicated cross-thematic ERANET for applied geosciences (GeoERA, 2017). Through this ERANET the many scientific challenges that separate us from a truly harmonized approach, will be addressed. Geological and technical solutions at different levels of the workflow will be developed and tested for energy, groundwater and minerals in various geological settings and regions of Europe. The results from this ERANET will be incorporated and shared through a common information platform (EGDI, 2016), which will connect regional and national geological databases in a single access point. The continued involvement of local and international stakeholders will assist the delivery of the Geological Service so that it will become an effective instrument for national and European endusers, and a reliable information source for the public. It is only through this European cooperation that the national and regional GSOs can continue to play their central role for society and economy, while guaranteeing that the geoethical principles of sustainability, transparency, verification, and objectivity are fully respected.

\section{ACKNOWLEDGEMENTS}

The content of this paper was shaped through numerous discussions with many colleagues from GSOs and other institutes, both European and non-European, as well as by experiencing the benefits of intense cooperation in crossborder projects. The authors would like to thank everyone that was to some degree involved, as well as the regional, national and international funding organizations that allowed building up to the GeoERA project. The GeoERA project (Establishing the European Geological Surveys Research Area to deliver a Geological Service for Europe) has received funding from the European Union's Horizon 2020 research and innovation program under grant agreement No. 731166.

\section{REFERENCES}

Andrews-Speed P., Bleischwitz R., Boersma T., Johnson C., Kemp G., VanDeVeer S.D. (2012). The Global Resource Nexus: The Struggles for Land, Energy, Food, Water, and Minerals. Transatlantic Academy.

Bazilian M., Rogner H., Howells M., Hermann S., Arent D., Gielen D., Steduto P. et al. (2011). Considering the energy, water and food nexus: Towards an integrated modelling approach. Energy Policy 39(12), 7896-7906. doi:10.1016/ j.enpol.2011.09.039.

Di Capua G., Peppoloni S. and Bobrowsky P.T. (2017). The Cape Town Statement on Geoethics, doi: 10.4401/ ag-7553. In: Peppoloni S., Di Capua G., Bobrowsky P., Cronin V.S. (Eds.), Geoethics at the heart of all geoscience, Annals of Geophysics, Vol 60, Fast Track 7.

EC (2007). Directive 2007/ 2/ EC of the European Parliament and of the Council of 14 March 2007: Establishing an Infrastructure for Spatial Information in the European Community (IN SPIRE). 
EC (2011). European Competitiveness Report 2011. Commission staff working document SEC(1011), 1188.

EC (2014). Communication from the Commission to the European Parliament, the Council, the European Economic and Social Committee and the Committee of the Regions: A policy framework for climate and energy in the period from 2020 to 2030. $\operatorname{COM}(2014), 15$.

EGDI (2016). European Geological Data Infrastructure, http:/ / www.europe-geology.eu (accessed 15 May 2018).

GEOERA (2017). Establishing the European Geological Surveys Research Area to deliver a Geological Service for Europe. European Union's Horizon 2020 research and innovation programme, grant agreement $\mathrm{No}$ 731166.

Hinsby K., Condesso de Melo M.T., and Dahl M. (2008). European case studies supporting the derivation of natural background levels and groundwater threshold values for the protection of dependent ecosystems and human health. Science of The Total Environment, volume 401, issue 1-3, pages 120, doi: 10.1016/ j.scitotenv.2008.03.018.

Liu J., Mooney H., Hull V., Davis S., Gaskell J., Hertel T., Lubchenco J. et al. (2015). Systems integration for global sustainability. Science 347(6225), 1258832, doi:10.1126/ science.1258832.

Martínez-Frías J., González J.L., and Pérez F.R. (2011). Geoethics and deontology: From fundamentals to applications in planetary protection. Episodes, 34(4), 257-262.

Peppoloni S. and Di Capua G. (2015). Introduction. In: Peppoloni S. and Di Capua G. (Eds.), Geoethics: the Role and Responsibility of Geoscientists, Geological Society, London, Special Publications, 419, ISBN 978-1-86239-726-2.

Peppoloni S. and Di Capua G. (2017). Geoethics: Ethical, Social and Cultural Implications in geosciences, doi:10.4401/ ag-7473. In: Peppoloni S., Di Capua G., Bobrowsky P., Cronin V.S. (Eds.), Geoethics at the heart of all geoscience, Annals of Geophysics, Vol 60, Fast Track 7.

Steffen W., Crutzen J., and McNeill J.R. (2007). The Anthropocene: are humans now overwhelming the great forces of Nature? Ambio 36(8), 614-21.
Steffen W., Richardson K., Rockström J., Cornell S., Fetzer I., Bennett E., Biggs R., et al. (2015). Su stainability. Planetary boundaries: guiding human development on a changing planet. Science, 347(6223), 1259855, doi:10.1126/ science. 1259855 .

Treidel H., Martin-Bordes J.L., Gurdak J.J., (eds.) (2012). Climate Change Effects on Groundwater Resources: A Global Synthesis of Findings and Recommendations. International Association of Hydrologists. 1st Edition.

United Nations (2015a). Sustainable Development Goals (SDGs), http:/ / www.un.org/ sustainable development/ sustainable-development-goals/ \#

United Nations (2015b). Transforming our world: the 2030 Agenda for Sustainable Development. Resolution adopted by the General Assembly on 25 September 2015 (70/ 1).

United Nations (2017). World Population Prospects 2017, https:/ / esa.un.org/ unpd/ wpp/ (accessed 15 May 2018)

United Nations (2018). Water Action Decade https:/ / www.un.org/ pga/ 72/ eventlatest/ launch-of-the-international-decadeof-w ater-for-su stainable-d evelopment-20182028/ (accessed 15 May 2018).

Van der Meulen M.J., Doornenbal J.C., Gunnink J.L., Stafleu J., Schokker J., Vernes R.W., Van Geer F.C., Van Gessel S.F., Van Heteren S., Van Leeuwen R.J.W., Bakker M.A.J., Bogaard P.J.F., Busschers F.S., Griffioen J., Gruijters S.H.L.L., Kiden P., Schroot B.M., Simmelink H.J., Van Berkel W.O., Van der Krogt R.A.A., Westerhoff W.E. and Van Daalen T.M. (2013). 3D geology in a 2D country: perspectives for geological surveying in the Netherlands. Netherlands Journal of Geosciences 92: 217-241. doi:10.1017/ S0016774600000184.

Wilkinson M., Dumontier M., Aalbersberg I.J., et al. (2016). The FAIR Guiding Principles for scientific data management and stewardship. Nature Scientific Data 3: sdata201618. doi:10.1038/ sdata.2016.18.

Wyss M. and Peppoloni S (eds.). (2015). Geoethics: Ethical Challenges and Case Studies in Earth Sciences. Elsevier, Waltham, MA, ISBN 978-0-12-799935-7. 